\title{
Social Network Activity and Social Well-Being
}

\author{
Moira Burke \\ Human-Computer Interaction Institute \\ Carnegie Mellon University \\ 5000 Forbes Ave., Pittsburgh, PA 15213 \\ moira@cmu.edu
}

\author{
Cameron Marlow and Thomas Lento \\ Facebook \\ 1601 S. California Ave. \\ Palo Alto, CA 94301 \\ \{cameron, lento\}@facebook.com
}

\begin{abstract}
Previous research has shown a relationship between use of social networking sites and feelings of social capital. However, most studies have relied on self-reports by college students. The goals of the current study are to (1) validate the common self-report scale using empirical data from Facebook, (2) test whether previous findings generalize to older and international populations, and (3) delve into the specific activities linked to feelings of social capital and loneliness. In particular, we investigate the role of directed interaction between pairs - such as wall posts, comments, and "likes"and consumption of friends' content, including status updates, photos, and friends' conversations with other friends. We find that directed communication is associated with greater feelings of bonding social capital and lower loneliness, but has only a modest relationship with bridging social capital, which is primarily related to overall friend network size. Surprisingly, users who consume greater levels of content report reduced bridging and bonding social capital and increased loneliness. Implications for designs to support well-being are discussed.
\end{abstract}

\section{Author Keywords}

Social network sites, social capital, loneliness, computermediated communication

\section{ACM Classification Keywords}

H.5.3 [Information Interfaces]: Group and Organization

Interfaces - Collaborative computing, Web-based

interaction, Computer-supported cooperative work

\section{SOCIAL CAPITAL AND SOCIAL NETWORKING SITES}

Social networking sites (SNS) complement the network of relationships present in the offline world by providing a platform for active communication between friends and more passive observation through aggregated streams of social news. Use of these sites has been associated with greater levels of social capital, or benefits made possible by the existence of a social structure [1]. These benefits include bridging social capital, or access to new information through a diverse set of acquaintances, and bonding social capital, or emotional support from close friends [9]. Ellison and colleagues show that students who are active on Facebook feel higher levels of both forms of social capital, and the effects are greater for students with lower self-esteem $[4,15]$. Heavy users of SNS also exhibit greater social trust and civic participation [16]. These studies use the Facebook Intensity

Permission to make digital or hard copies of all or part of this work for personal or classroom use is granted without fee provided that copies are not made or distributed for profit or commercial advantage and that copies bear this notice and the full citation on the first page. To copy otherwise, or republish, to post on servers or to redistribute to lists, requires prior specific permission and/or a fee.

CHI 2010, April 10-15, 2010, Atlanta, Georgia, USA.

Copyright 2010 ACM 978-1-60558-929-9/10/04 ...\$10.00
Scale $[4,15]$, which is based on self-reports of time online and number of friends, along with six attitude items like "Facebook has become part of my daily routine." One of the goals of this study is to determine how well people self-report these values by comparing them with Facebook activity logs. With few exceptions [14], these kinds of studies have focused on college students, and so we also test whether previous findings generalize to older users and those outside the U.S.

Early studies of the Internet examined the correlation between time online with outcomes such as loneliness [7], but later studies differentiate between social activities and pure entertainment, finding different results for different activities $[6,18]$. Similarly, current studies of SNS do not distinguish between time spent chatting with friends and time taking quizzes, raising a question as to how precisely "social" these interactions are. This question of "how social is social" may also be changing as the Internet becomes a more pervasive technology - earlier studies of social interaction online tended to show Internet or SNS users as lonely because the pool of interactants was small, while today Facebook claims a worldwide user base of 350 million users, most of whom also have their entire social circles on the site. As such, social psychologists and site designers would benefit from a more nuanced understanding of what SNS users are actually doing, and the relationship between their feature use and feelings of connection to others. Therefore, the main goal of this study is to tease out the relative weight of different activities and their relationship to three measures of social well-being: bridging social capital, bonding social capital, and loneliness.

\section{DIRECTED COMMUNICATION AND CONSUMPTION}

In the present study, we distinguish between two types of activity: directed communication and consumption. Directed communication consists of interactions on the site between the focal user and another friend (including actions like photo tagging), in which one friend directly identifies another. Wall posts and messages are strong predictors of relationship strength [5], and one-on-one chat sessions are associated with reduced loneliness and depression [13]. Therefore, we predict:

H1. Bonding social capital will increase with the amount of direct communication.

H2: Loneliness will decrease with the amount of direct communication.

However, recent work has shown that users only interact with a small core of their friend network, even as their overall network size grows [3]. For the majority of their networks, we expect users keep track of their friends' activities through the "feed," an aggregated stream of social news. Therefore, we 
consider consumption to include the monitoring of all of the content that is not specifically targeted at a given user, including friends' "broadcasts" to wide audiences (e.g., status updates), or public conversations by the user's friend with others. We predict that users maintain their large, diverse networks through this more passive form of site use:

\section{H3. Bridging social capital will increase with consumption.}

The relationship between consumption and loneliness is more complex. Reading stories about friends' activities could cause a user to feel embedded in a social circle or left out. Lonely individuals could gravitate toward the feed because it reduces social boundaries, or they could avoid it because it reifies the social distance they feel face-to-face. Thus, we simply predict:

\section{H4. Consumption will be associated with loneliness.}

\section{METHOD}

To analyze the relationship between social well-being and SNS activity, we examined survey data containing standard well-being scales and server logs of the participants' activity on Facebook for the two months prior to the survey.

\section{Social well-being survey}

Participants $(\mathrm{N}=1193)$ were recruited via an ad on Facebook targeted at English-speaking adults. The survey included five items each from the bonding and bridging scales in $[4,17]$. Bridging items (scale alpha=.75) included "I come in contact with new people all the time," and bonding (alpha=.69) included "There are several people I trust to help solve my problems." Eight items from the UCLA loneliness scale [11] were included (alpha=.86), such as "I often feel close to people." All responses were given on 5-pt Likert scales ranging from "strongly disagree" to "strongly agree." The loneliness items were adjusted to fit an agree-disagree scale. A subset of users $(n=155)$ was also given the eight-item Facebook Intensity Scale $[4,15]($ alpha $=.80)$ to validate users' self-reports of site activity.

\section{Activity on SNS}

We collected activity data for each survey participant for the two months prior to the survey. Survey-takers who had joined the site less than two months prior were dropped. All variables were aggregated from server logs using the Hadoop distributed computation platform. Data were analyzed in aggregate so that no individual's actions, friend networks, or identifiable information were used.

All of the activity variables follow power law distributions, and thus we use the logarithm (base 2, after adding a startvalue of 1) of these variables to control for skew and then standardize by centering at the mean and dividing by the standard deviation. Because activity variables are highly correlated with each other, scale values were created for content production, directed communication and consumption by taking the mean of the standardized values. The content production scale is used as a measure of overall site engagement, along with number of friends and time spent on the site. Scale alphas and descriptive statistics for the raw variables are reported in Table 1.

\section{Directed communication}

This scale includes interactions on the site between the focal user and another friend, including text exchanges, non-text

\begin{tabular}{|c|c|c|}
\hline & Mean & $\mathrm{SD}$ \\
\hline \multicolumn{3}{|c|}{ Controls } \\
\hline Age (in years) & 33.7 & 13.1 \\
\hline Male $(0 / 1)$ & $37 \% \mathrm{n}$ & \\
\hline
\end{tabular}

Countries with more than 60 participants: United States, Great Britain, Canada, Ireland, New Zealand, South Africa. Plus 15 others.

In relationship $(0 / 1)$

$50 \%$ in relationship

Self-esteem

$3.9 \quad 0.71$

Life satisfaction

$3.3 \quad .89$

General site engagement

Time on site (avg. hours per day)

Friend count

Content produced (scale $\alpha=0.69$ )

Status updates $(\alpha=.70)$

Notes written $(\alpha=.70)$

Photos posted $(\alpha=.63)$

Application stories posted $(\alpha=.65)$

Other items posted to own wall $(\alpha=.62)$

Directed communication and content consumption

Directed communication (scale $\alpha=.94$ )

Friends who initiated communication with user $(\alpha=.91) 35.2$

Wall posts received $(\alpha=0.71)$

$4.23 \quad 8.7$

Messages received $(\alpha=.78)$

$52.7 \quad 114.0$

Comments received $(\alpha=.89)$

$42.0 \quad 125.0$

"Likes" received $(\alpha=0.84)$

$26.8 \quad 45.4$

Times tagged in photo $(\alpha=0.65)$

$\begin{array}{ll}14.6 & 30.5\end{array}$

Friends user initiated communication with $(\alpha=.89)$

Wall posts written $(\alpha=.73)$

$42.6 \quad 43.0$

Messages written $(\alpha=.75)$

Comments written $(\alpha=.86)$

"Likes" given $(\alpha=.76)$

$\begin{array}{ll}5.0 & 9.0\end{array}$

$63.3 \quad 158.6$

$147.6 \quad 208.27$

$39.4 \quad 70.1$

Times tagged friend in photo $(\alpha=.68)$

Content consumption (scale $\alpha=0.86$ )

Friends whose feed stories user clicked on $(\alpha=.90)$

Distinct profiles viewed $(\boldsymbol{\alpha}=.89)$

Distinct photos viewed $(\alpha=.77)$

$27.3 \quad 74.5$

$0.0 \quad 0.86$

$60.3 \quad 59.2$

$133.8 \quad 147.21$

$3.9 \quad 9.48$

$747.6 \quad 901.6$

Times reloaded news feed $(\alpha=.85)$

Table 1. Descriptive statistics. Cronbach's alpha is reported for activity scales and for individual items with the whole scale.

feedback such as clicking the "like" button, and photo tagging. The number of distinct friends who initiated directed actions or were the target of directed actions was also included. Giftgiving, "pokes" and video- and note-tagging were excluded because few participants in the sample used these features.

\section{Consumption}

This scale measures the degree to which the user paid attention to the general broadcasts shared by his or her friends, including status updates and public conversations by the user's friend with someone else. Attention is measured as feed story clicks. We also include the number of distinct profiles viewed, distinct photos viewed, and distinct friends on whose news stories the focal user clicked.

\section{Controls}

The age, gender, and country listed on participants' accounts were included as controls. Romantic relationship status was 
coded as a dummy variable, with a value of 1 for anyone married, engaged, or in a relationship, and 0 for everyone else, including those who did not provide their status. Survey measures of self-esteem [10] (alpha $=.87$ ) and satisfaction with life [2] (alpha $=.87$ ) were included as controls, as in [4].

\section{RESULTS}

To determine survey non-response bias, activity data were pulled for an equal-sized random sample of English-speaking adults who had used the site in the past 30 days. Survey takers were slightly older $(\mathrm{M}=33.7$ vs. 33.0 years, $p<.05)$, spent more time on the $\operatorname{site}^{1}(\mathrm{M}=1.7$ hours per day vs. $0.5, p<.001)$, had more friends ( $\mathrm{M}=185.6$ vs. $170.0, p<.001)$, were more likely to be women $\left(\mathrm{X}^{2}=27.3, p<.001\right)$, and less likely to be from the U.S. $\left(X^{2}=270.2, p<.001\right)$. Sensitivity analyses on users with fewer than 50 friends, $50-150,150-400$, and $400+$ friends provide qualitatively similar well-being results.

\section{General site engagement and social well-being}

Table 2 presents general OLS models using controls and overall site engagement variables. Older users reported lower levels of bonding social capital, but age had no impact on bridging social capital or loneliness. Men were lonelier and felt less bonding social capital than women. Self-esteem had a large effect on all three outcomes in the expected direction, and satisfaction with life was associated with increased bonding social capital and decreased loneliness.

Consistent with previous survey-based research, overall SNS activity, particularly friend count, was positively correlated with both kinds of social capital. It was also negatively correlated with loneliness. Time on site was highly correlated with friend count $(\mathrm{r}=.59)$ and content produced $(\mathrm{r}=.60)$; after controlling for friend count it was not a significant predictor of any of the well-being scores. Content production was associated with increases in bridging social capital. Results also hold for samples of non-college-aged adults and those outside the US. Analyses on the subsets of users over age 35 $(\mathrm{N}=487$, mean age 47.2) and those outside the US ( $\mathrm{N}=993)$ were of similar magnitude and significance.

\section{Validation of Facebook Intensity Scale}

Participants' self-reports of friend counts were highly correlated with actual friend counts $(\mathrm{r}=.96)$, most likely because the value is easy to find on one's Facebook home page. Self-reports of time spent on the site were moderately correlated with actual time $(\mathrm{r}=.45)$ after capping eight outliers at $500 \mathrm{~min} /$ day. The six attitude questions collapsed into a single scale were only slightly correlated with other measures of engagement, such as content production $(\mathrm{r}=.18)$ and number of days on site in the past month ( $\mathrm{r}=.14)$.

\section{Directed communication and content consumption}

Table 3 presents models that include directed communication and consumption. Directed communication has the predicted relationships to bonding social capital and loneliness, confirming $\mathrm{H} 1$ and $\mathrm{H} 2$. Bridging social capital is primarily predicted by friend count. However, it is surprising to see that

\footnotetext{
${ }^{1}$ t-tests were performed on site time and friend count using log-transformed data to account for skew, but non-transformed means are reported for interpretability.
}

\begin{tabular}{|c|c|c|c|c|c|c|}
\hline Model 1 & \multicolumn{2}{|c|}{ Bridging } & \multicolumn{2}{|c|}{ Bonding } & \multicolumn{2}{|c|}{ Loneliness } \\
\hline & B & SE & B & $\mathrm{SE}$ & B & SE \\
\hline Intercept & $3.95 * * *$ & .05 & $3.85 * * *$ & .06 & $2.46 * * *$ & .05 \\
\hline Age & .00 & .00 & $-.01 * *$ & .00 & .00 & .00 \\
\hline Male & -.03 & .04 & $-.11 * *$ & .04 & $.10 * *$ & .04 \\
\hline In relationship & $-.11 * *$ & .04 & -.05 & .04 & $-.08 *$ & .04 \\
\hline Self-esteem & $.23 * * *$ & .03 & $.31 * * *$ & .04 & $-.53 * * *$ & .03 \\
\hline Life satisfaction & .02 & .02 & $.10 * * *$ & .03 & $-.16 * * *$ & .02 \\
\hline Time on site $(\log 2)$ & -.05 & .03 & .02 & .03 & .03 & .03 \\
\hline Friend count $(\log 2)$ & $.14 * * *$ & .03 & $.12 * * *$ & .03 & $-.08 * *$ & .03 \\
\hline Content produced & $.09 * *$ & .03 & -.04 & .04 & .01 & .03 \\
\hline & $\mathrm{R}^{2}=.12$ & & $\mathrm{R}^{2}=.18$ & & $\mathrm{R}^{2}=.41$ & \\
\hline
\end{tabular}

Table 2. OLS regressions for bridging and bonding social capital and loneliness based on overall SNS activity. Countries omitted for space.

\begin{tabular}{lcc|cc|cc}
\multicolumn{1}{c}{ Model 2 } & \multicolumn{2}{c}{ Bridging } & \multicolumn{2}{c}{ Bonding } & \multicolumn{2}{c}{ Loneliness } \\
\hline Intercept & $\mathrm{B}$ & $\mathrm{SE}$ & $\mathrm{B}$ & $\mathrm{SE}$ & $\mathrm{B}$ & $\mathrm{SE}$ \\
Age & $3.93 * * *$ & .05 & $3.84 * * *$ & .06 & $2.49 * * *$ & .05 \\
Male & .00 & .00 & $-.01 * *$ & .00 & .00 & .00 \\
In relationship & -.02 & .04 & $-.10 *$ & .04 & $.08 *$ & .04 \\
Self-esteem & $.11 * *$ & .04 & -.05 & .04 & $-.09 *$ & .04 \\
Life satisfaction & .02 & .02 & $.10 * * *$ & .03 & $-.16 * * *$ & .02 \\
Time on site $(\log 2)$ & .00 & .04 & .06 & .05 & -.04 & .04 \\
Friend count (log2) & $.14 * * *$ & .03 & $.09 *$ & .04 & $-.07 *$ & .03 \\
Content produced & .07 & .04 & -.09. & .05 & .04 & .04 \\
Directed & & $.30 * * *$ & .04 & $-.53 * * *$ & .03 \\
communication & .08. & .04 & $.11 *$ & .05 & $-.11 *$ & .04 \\
Consumption & $-.10 *$ & .04 & -.09. & .04 & $.15 * * *$ & .04 \\
& \multicolumn{2}{c}{$\mathrm{R}^{2}=.12$} & \multicolumn{2}{c|}{$\mathrm{R}^{2}=.19$} & & $\mathrm{R}^{2}=.42$ \\
\hline
\end{tabular}

Table 3. Models including directed communication and consumption

controlling for friend count and direct communication, consumption is associated with reduced bridging social capital (disproving H3) and increased loneliness (confirming H4). It also trends negative for bonding social capital $(p=.06)$.

\section{DISCUSSION}

The present study confirms previous survey-based findings that greater SNS use is associated with increased social capital and reduced loneliness. This can be interpreted in many ways: (1) people who feel more socially connected gravitate toward technical systems that reify those connections, (2) using sites like Facebook allows people to reinforce fledgling and distant relationships, or (3) there is a positive feedback loop. We also confirm that these findings generalize to older users and English-speakers outside the U.S. and show that the common tool for estimating SNS use, the Facebook Intensity Scale, 
correlates relatively well with actual site behavior. Users are generally good at self-reporting their friend count and time on site. The present results suggest that asking for friend count and time on site is sufficient to measure intensity, as the attitudinal self-reports did not correlate with plausible engagement metrics. It is possible there are server data that correlate more strongly with the attitude reports, and we will continue to look for long-term engagement in the next waves of this longitudinal study. In prior studies, attitudinal selfreport measures have shown problems such as central tendency and acquiescence bias [e.g., 8,12], but server data such as days online in the previous month may not capture a user's full experience of engagement. Overall, however, the present study suggests the attitude scales are unnecessary.

Directed communication plays the expected role in bonding social capital. Messages exchanged between friends are both a product of the friendship and a means of facilitating and maintaining such friendships. However, the results for consumption are somewhat surprising, as after controlling for directed communication users who click on lots of stories about their friends report reduced bridging social capital. One interpretation is that to reap the benefits of a diverse network, you need to both have a diverse set of weak ties and the communication context to take advantage of them.

The results are less surprising for loneliness: People who feel a discrepancy between the social interactions they have and those that they desire tend to spend more time observing other people's interactions. Whether the loneliness causes the clicking, or the clicking causes the loneliness is left to the future waves of this study.

One interpretation of these findings is that our measure of consumption could encode "noise" in the user experience. That is, as users have more low-quality content in their feed, they may come to feel less connected with their friends. This effect is mitigated by our approach, which only considers stories that users click on. Furthermore, an analysis of subset of clicks on the Highlights feed-a form of the feed in which content is ordered by friends' interactions - shows the same effects, suggesting that these results are not due to noise.

Apart from the relationship between consumption and increased loneliness, we see that engagement with Facebook is correlated with greater overall well-being. This association speaks to a number of potential design enhancements for fostering communication over passive engagement. Users who appear to be exhibiting behaviors associated with loneliness, such as over-consuming for their level of direct communication, could be the target of interventions of content they are likely to interact with, or exposed to users with whom they have not conversed recently. Likewise, content produced by these users could be exposed to friends who might directly interact with them. While we cannot speak to causality at this stage of our study, these features could be validated through simple experimentation.

\section{Limitations and future work}

This work represents a comprehensive analysis of the relationship between Facebook usage and social well-being, although we expect these effects to generalize to other SNS. Since we do not have the responses of people who choose not to use social networking online, it is not possible to understand the bias introduced by our sample. While we have extended these results to an international, English-speaking audience, other languages are likely associated with varying beliefs about group interaction, individualism, and other cultural norms that may greatly affect the results. Finally, the results do not speak to causality. We plan to repeat the survey with the same participants over two 6-month intervals and use a cross-lag analysis to observe the potentially causal relationship between SNS usage and social well-being.

\section{REFERENCES}

1. Coleman, J.S. (1988). Social capital in the creation of human capital. American journal of sociology 94, S1 (1988), 95.

2. Diener, E., Suh, E., \& Oishi, S. (1997). Recent findings on subjective well-being. Indian J. of Clinical Psychology, 24 (1), 25-41.

3. Economist.com (2009, Feb 26). Primates on Facebook. The Economist. http://www.economist.com/sciencetechnology/displayStory.cfm?story_id=13176775

4. Ellison, N. B., Steinfield, C., \& Lampe, C. (2007). The benefits of Facebook "friends:" Social capital and college students' use of online social network sites. JCMC 12(4).

5. Gilbert, E. and Karahalios, K. Predicting tie strength with social media. Proceedings of the 27 th international conference on Human factors in computing systems, (2009), 211-220.

6. Kraut, R., Kiesler, S., Boneva, B., Cummings, J., Helgeson, V., \& Crawford, A. (2002). Internet Paradox Revisited. J. of Social Issues, 58 (1), 49-74.

7. Kraut, R., Patterson, M., Lundmark, V., Kiesler, S., Mukopadhyay, T., \& Scherlis, W. (1998). Internet paradox: A social technology that reduces social involvement and psychological well-being? American Psychologist, 53 (9), 1017-1031.

8. Krosnick, J.A. (1999). Survey Research. Annual Review of Psychology 50, 1 (1999), 537-567.

9. Putnam, R.D. Bowling alone: The collapse and revival of American community. Simon \& Schuster, 2000.

10. Rosenberg, M. (1989). Society and the Adolescent Self-Image (Rev. ed.). Middletown, CT: Wesleyan University Press.

11. Russell D.W. (1996). UCLA loneliness scale: reliability, validity, and factor structure. J. of Personality Assessment 66(1), 20-40.

12. Schwarz N., Hippler H., Deutsch B., Strack F. (1985). Response scales: effects of category range on reported behavior and subsequent judgments. Public Opinion Quarterly 49: 388-95

13. Shaw, L. \& Gant, L. (2002). In defense of the Internet: The relationship between Internet communication and depression, loneliness, self-esteem, and perceived social support. CyberPsychology \& Behavior 5(2), 157-172.

14. Steinfield, C., DiMicco, J.M., Ellison, N.B., and Lampe, C. Bowling online: social networking and social capital within the organization. Proceedings of the fourth international conference on Communities and technologies, (2009), 245-254.

15. Steinfield, C., Ellison, N. \& Lampe, C. (2008). Social capital, self-esteem, and use of online social network sites: A longitudinal analysis. J. of Applied Developmental Psychology 29 (6).

16. Valenzuela, S., Park, N., and Kee, K. (2009) Is There Social Capital in a Social Network Site?: Facebook Use and College Students' Life Satisfaction, Trust, and Participation. JCMC 14(4), 875-901.

17. Williams, D. (2006). On and off the 'net: Scales for social capital in an online era. JCMC, 11(2), article 11.

18. Zhao, S. Do Internet users have more social ties? A call for differentiated analyses of Internet use. JCMC 11, 3 (2006), 844-862. 